\title{
The Swelling of Bacterial Spores during Germination and Outgrowth
}

\author{
By A. D. HITCHINS, G. W. GOULD AND A. HURST \\ Unilever Research Laboratory, Colworth House, Sharnbrook, Bedford
}

(Received 25 June 1962)

\begin{abstract}
SUMMARY
The swelling of spores of Bacillus cereus and B. subtilis during germination and outgrowth was followed by measuring changes in packed cell volume (pcv) and by photomicrographic measurements of single organisms. Three stages of swelling were recognized: (1) germination swelling involving a rapid increase of about $20 \%$ in pcv as the spore germinated; (2) preemergence swelling of up to $100 \%$ increase in pcv before emergence from the spore coat; (3) elongation. Germination swelling was due mainly to an increase in the breadth of the spore. It occurred in the absence of oxygen and was not inhibited by nisin whereas pre-emergence swelling was oxygen-dependent and was inhibited by nisin. Post-emergence swelling occurred during elongation of the new vegetative form. The significance of these findings is discussed.
\end{abstract}

\section{INTRODUCTION}

The transition from a dormant bacterial spore to a dividing vegetative form used to be termed germination. However, recent research has shown that this transition may be divided into several distinct stages. The term germination is thus now reserved for the first stage, and the transformation of the germinated spore into the vegetative form is called outgrowth (Campbell, 1957) or post-germinative development (Levinson \& Hyatt, 1956). Germination involves loss of resistance to heat and other injurious agents, loss of refractivity when examined by the phase-contrast microscope (Pulvertaft \& Haynes, 1951), decrease in optical density of suspensions and increase in stainability of cells (Powell, 1950), decrease in dry weight due to loss of dipicolinic acid, calcium and a non-dialysable mucopeptide (Powell \& Strange, 1953) and the initiation of respiration (Murrell \& Scott, 1958). Germination is induced by simple nutrients and may be differentiated from outgrowth by certain inhibitors (Murty \& Halvorson, 1957; Halvorson, 1959). Temperature requirements for germination are often different from those for outgrowth (Mol, 1957; Wolf \& Mahmoud, 1957). Outgrowth includes four stages occurring in the following order: swelling, emergence from the spore coat, elongation of the emergent organism, and finally division of the elongated organism. Each stage is characterized by different requirements. For example oxygen uptake becomes detectable during germination, increases in rate during swelling and increases still further after emergence (Mandels, Levinson \& Hyatt, 1956). Phosphates are required early in the outgrowth process (Hyatt \& Levinson, 1959), but sulphur only becomes essential later on (Hyatt \& Levinson, 1957); different metal ions are toxic to different stages of outgrowth 
(Hyatt \& Levinson, 1957). The changes occurring during and after germination can thus be grouped into one or other of two major processes, which are: (i) the breakdown of spore structure; (ii) the synthesis of new vegetative cell material. These two processes have been intensively studied, but the swelling of spores has received little attention. We have therefore studied changes in the volume of spores during germination and outgrowth and related these changes to the stages of development.

\section{METHODS}

Cultures. The organisms used were Bacillus cereus NCTC 945 and $B$. subtilis м3, a laboratory isolate. Both conformed to the descriptions of these species given by Smith, Gordon \& Clark (1946).

Production and cleaning of spores. Organisms were grown at $30^{\circ}$ on Oxoid potato extract agar reinforced with $1 \%(\mathrm{w} / \mathrm{v})$ yeast extract (Difco) and adjusted to $\mathrm{pH} 7$. When sporulation was complete and lysis of the sporangia had occurred, the freed spores were washed off the agar with cold water and washed a further three times with cold water by centrifuging. Suspensions were cleaned by repeatedly centrifuging and discarding the uppermost layers of the pellets (Long \& Williams, 1958). Efficient cleaning was necessary because any cell debris contaminating the spore suspensions interfered with measurements of volumes of packed spores. Furthermore, the packed volume of cell debris in suspensions which had not been cleaned was variable; for instance it decreased when suspensions were heated, probably because of disruption or coagulation of cytoplasmic debris. This did not occur with cleaned spores. Spore suspensions were stored at $4^{\circ}$ in water and activated by heating at $70^{\circ}$ for $30 \mathrm{~min}$. before use, to ensure rapid germination.

Experimental technique. Spore suspensions $\left(70 \mathrm{ml}\right.$.) were warmed to $37^{\circ}$ and rapidly mixed with an equal volume of yeast glucose broth (YGB) also at $37^{\circ}$. At the same time a stop-watch was started. Samples $(25 \mathrm{ml}$.) were removed at intervals and rapidly pipetted into bottles precooled in ethanol and solid $\mathrm{CO}_{2}$ mixture and then stored in ice water until required. This cooling procedure effectively arrested the development of spores and enabled optical measurements to be made.

A drop of the same suspension was spread on a prewarmed microscope slide so that it quickly dried. This was stained by a modified Ziehl-Neelsen stain (Powell, 1950), and viewed with a light microscope. Another drop of the suspension was viewed with a phase-contrast microscope. The two microscopic methods and measurements of the optical density of suspensions at $580 \mathrm{~m} \mu$ were used to determine the extent of germination and outgrowth.

Measurement of packed cell volume (pcv). Samples were centrifuged at $2000 \mathrm{~g}$ for $20 \mathrm{~min}$. at $4^{\circ}$ and the pellets drained. Each pellet was then emulsified in 0.5 or $1.0 \mathrm{ml}$. of saline at $4^{\circ}$ containing 2 drops of capryl alcohol $/ 100 \mathrm{ml}$. to prevent foaming. These concentrated samples were drawn into M.S.E. capillary haematocrit tubes and centrifuged at $2700 \mathrm{~g}$ for $15 \mathrm{~min}$. at $4^{\circ}$ in the M.S.E. microhaematocrit centrifuge head (Measuring and Scientific Equipment Ltd., London, S.W. 1). The length of the pellet and the total liquid length in each capillary tube were measured with a travelling microscope with vernier scale. The packed cell volume (pcv) was expressed as a \% by using the formula: $\mathrm{pcv}=$ length of pellet $(\mathrm{mm}) \times$. length of pellet+length supernatant fluid (mm.) 
Photomicrographic measurements. Suspensions of spores (about $10^{7} / \mathrm{ml}$.) were dried on 1 in. square no. 0 cover glasses. These were placed on flat pads of yeast glucose agar (about $1 \mathrm{~mm}$. in thickness) on $1 \times 3$ in. microscope slides in a microscope stage incubator at $37^{\circ}$. A group of spores was immediately brought into focus and photographed, first under phase-contrast illumination then under light field illumination. At intervals photography of the same group of spores was repeated so that the successive stages of development were recorded. The micrographs were enlarged and printed at final magnifications of $\times 3840$ (Bacillus subtilis) or $\times 2400$ (B. cereus). Lengths and breadths of phase and light field photographs of individual organisms were measured. In addition to measuring cell size, an estimate of the stage of germination reached by each spore was made from its appearance under phase-contrast illumination. These were recorded as: (1) phase bright ungerminated spore; (2) first sign of phase darkening; (3) germinating but not fully phase-dark spore; (4) germinated fully phase-dark spore. Measurements of each spore were plotted against time, and the stage of germination was related to change in size.

\section{RESULTS}

\section{The effect of spore concentration on swelling}

Figure 1 shows the effect of spore concentration on the increase in packed cell volume (pcv) of Bacillus subtilis spores in medium which was not agitated (i.e. aeration was solely by diffusion through the liquid surface). Spore concentration was expressed as the initial pcv of the suspensions. The concentrations used were roughly doubling. The curves show that the rate of swelling was inversely dependent on the spore concentration. The rate of germination was such that $98 \%$ of the spores had germinated at all three concentrations within the first $25 \mathrm{~min}$. The initial increase of about $20 \% \mathrm{pcv}$, which occurred within the first $25 \mathrm{~min}$., was not decreased by increasing the spore concentration and swelling began at the same time as germination, without a lag phase. These results suggested that there might be two phases of swelling, the first occurring synchronously with germination and not dependent on spore concentration, and the second a post-germinative swelling which was dependent on spore concentration. Since the suspensions used were concentrated and not well aerated, oxygen was the obvious choice for the role of rate-limiting nutrient.

\section{The effect of aeration on swelling}

The increase in pcv of Bacillus subtilis spores under conditions of good and poor aeration is shown in Fig. 2. With a constant spore concentration (4.5\% initial pcv) the increase in pcr depended on the aeration rate. Germination was not affected by poor aeration, $98 \%$ germination occurred in $25 \mathrm{~min}$. in each case. However, with poor aeration (static culture with a small surface area), although germination occurred rapidly there was only a small increase in pcv of about $20 \%$ and no post-germinative swelling; after $80 \mathrm{~min}$. no outgrowth was observed. Figure 2 therefore shows that the effect of spore concentration (Fig. 1) was due to a deficiency of oxygen rather than of any other nutrient. Germination swelling still occurred when the oxygen tension was further lowered by bubbling nitrogen through the medium. Germination was therefore always accompanied by an increase in pev, and this increase could be differentiated from the post-germinative increase in pcv. 


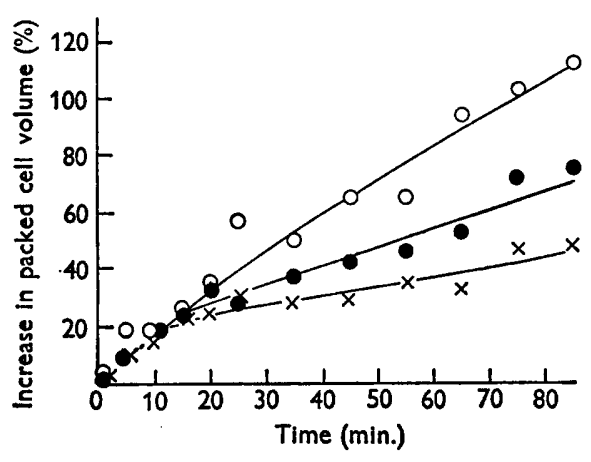

Fig. 1

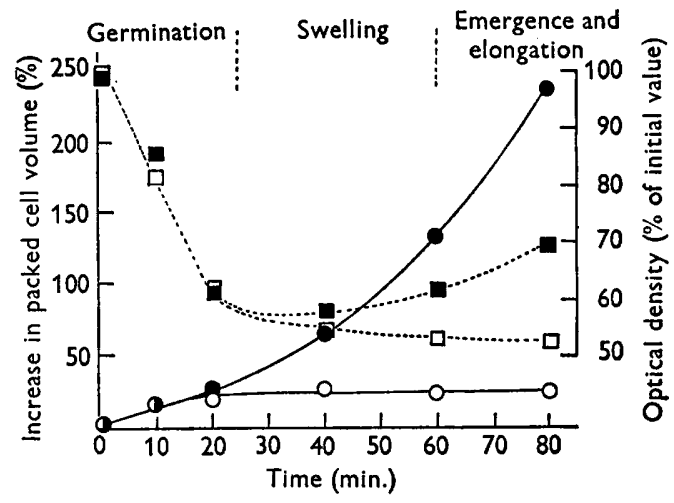

Fig. 2

Fig. 1. Effect of spore concentration on the increase in pev of Bacillus subtilis spores. Spores incubated in yeast glucose both at $37^{\circ}$. Germination was $98 \%$ complete in 25 min. and no emergence occurred in $80 \mathrm{~min}$. Spore concentration is expressed as the initial packed cell volume: $\bigcirc-0,2 \cdot 2 \% \mathrm{pcv} ;-4.1 \% \mathrm{pcv} ; \times-\times 7 \cdot 8 \% \mathrm{pcv}$.

Fig. 2. Effect of aeration on the increase in pcv of Bacillus subtilis spores. The initial packed cell volume was $4.5 \%$ for both cultures.

, Packed cell volumes; - - - , optical density; $\odot$, and $\square$, well-aerated culture; $\bigcirc$ and $\square$, poorly aerated culture.

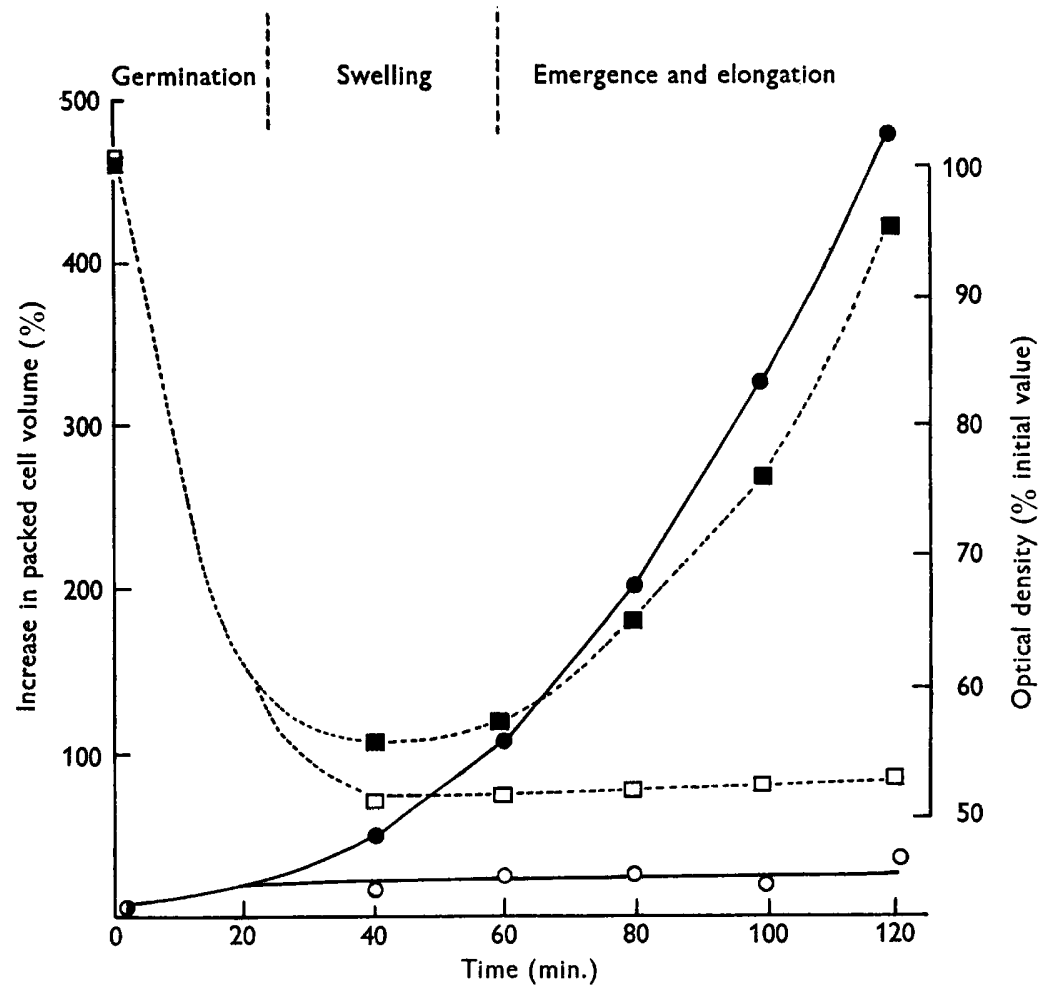

Fig. 3. Effect of nisin $(0.5 \mu \mathrm{g} . / \mathrm{ml}$.) on the increase in pcv of Bacillus subtilis spores. The initial pcv were $3.1 \%$ and both cultures were well aerated. - , pcv; - - - - , optical density; 0 and $\square$, in absence of nisin; $O$ and $\square$, in presence of nisin. 
Increase in spore volume also occurred during the germination of Bacillus cereus NCTC 945 spores and could be measured photomicrographically. However, the presence of exosporia around these spores made the increase in pcv that occurred during germination swelling appear relatively smaller. This fact coupled with the error of the pcv technique resulted in variable measurements. Post-germination and pre-emergence increase in pcv was readily detected.

\section{The effect of nisin on swelling}

Nisin is known to allow spores of sensitive organisms to germinate but to prevent their outgrowth (Campbell \& Sniff, 1959). The actual stage of outgrowth inhibited is coat rupture, and since Bacillus subtilis is sensitive to nisin it was of interest

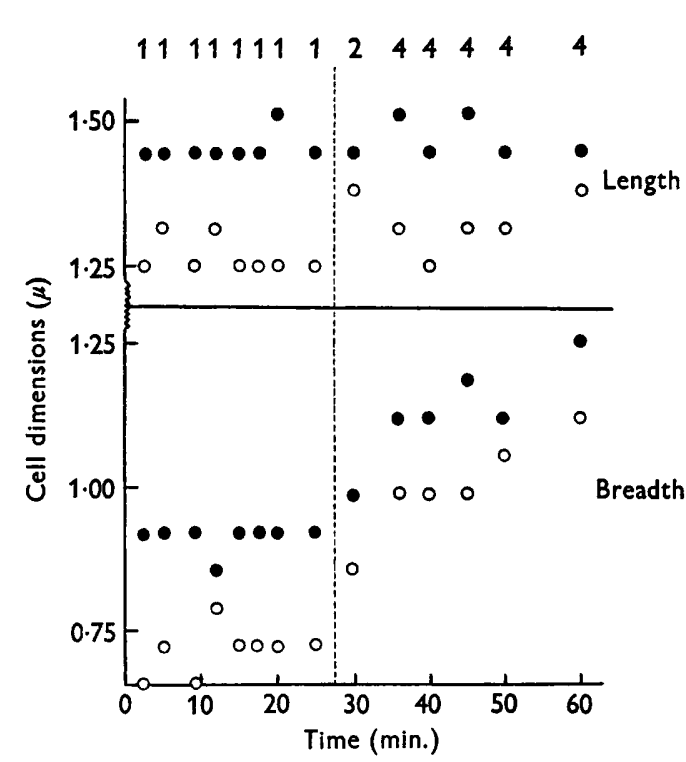

Fig. 4

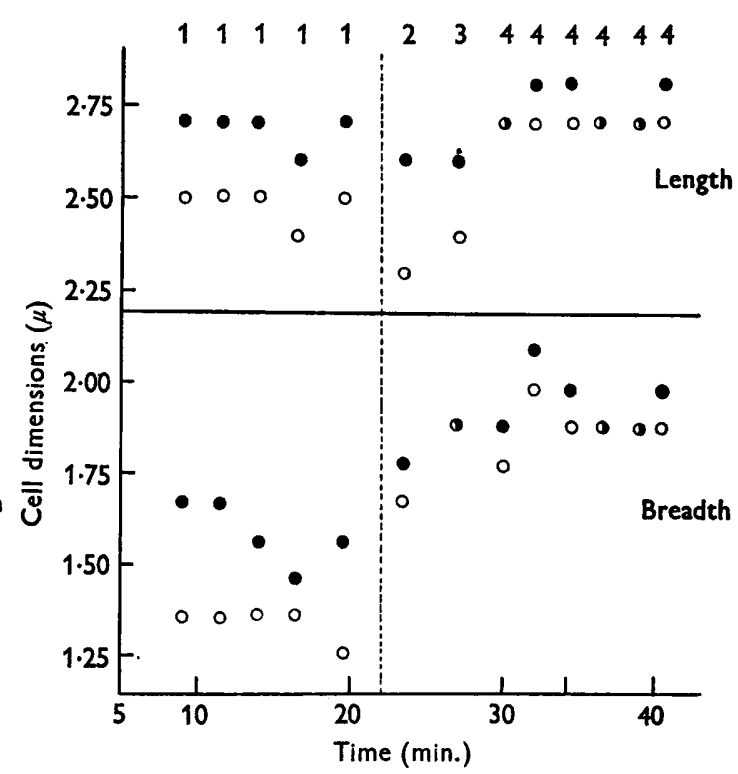

Fig. 5

Fig. 4. The length and breadth of a typical Bacillus subtilis spore during germination. Measurements from phase-contrast photomicrographs (O) and light-field photomicrographs (O). Key to stages of germination: 1, phase-bright ungerminated spore; 2, first sign of germination and phase-darkening; 3, germinating but not fully phase-dark spore; 4, germinated, fully phase-dark spore. Stage 3 was not observed with this particular spore.

Fig. 5. The length and breadth of a typical Bacillus cereus spore during germination. Measurements from phase-contrast photomicrographs (O) and light-field photomicrographs (O). Identical phase and light-field measurements are shown thus: 1 . Key to stages of germination as in Fig. 4.

to find what effect nisin had on spore swelling. Figure 3 shows the result of incubating spores in a well-aerated medium containing an inhibitory concentration of nisin. The initial swelling occurred as before, accompanying germination of the spores, but nisin was effective immediately after germination, for no post-germinative swelling occurred. This again suggests that the small constant germination-swelling 
is distinct from the swelling of the germinated spore, which occurs before emergence of the vegetative forms.

\section{Germination swelling observed microscopically}

Figures 4 and 5 show length and breath measurements of typical Bacillus subtilis and $B$. cereus spores before, during and after germination. Photographs taken with phase contrast and light-field illumination both revealed that during the change from the refractile ungerminated spore to the non-refractile germinated spore, cell breadth increased by about $40 \%$ whilst length increased only slightly (about $5 \%$ ). The change in shape can be seen in $\mathrm{Pl} .1$ and 2, and corresponds to the increase in pcr measured during germination. It is also noticeable that the increase in breadth of individual spores occurred rapidly and at the first sign of germination; i.e. germination-swelling takes place concurrently with germination and does not closely follow it.

\section{DISCUSSION}

Powell (1957) reported that swelling occurs after phase darkening and therefore after germination. Rode \& Foster (1960) stated that the germination process itself is characterized by slight swelling. Black \& Gerhardt (1962) also referred to several other authors who have reported swelling during germination. In the present work we have attempted to correlate these observations by describing swelling quantitatively and by relating it to the germination process. In what follows the results are discussed in relation to the facts known about germination.

The sudden increase in size and change in shape of spores during the very first phase of germination indicates that the spore coat must become elastic very early in the process, i.e. during the loss of dipicolinic acid, calcium and spore mucopeptide, since these events all follow closely the fall in optical density of the suspension and other changes that collectively constitute germination. Is weakening of the spore coat, for instance by partial lysis with enzymes, the event that starts the process or is weakening of the coat a subsequent event? The synchrony of germinationswelling with other changes that define germination suggests that the former is more probable. Strange \& Dark $(1957 a, b)$ described enzymes which attacked spore coats. If the mucopeptide released early in the germination process is derived from the spore coat, then early enzymic weakening of this structure seems likely. Furthermore, nisin prevents the rupture or lysis of spore coats during emergence but does not inhibit germination or germination swelling. Of course changes in spore shape and volume do not necessarily involve weakening of the spore coat, but might reflect changes in the properties of some underlying structure, such as the cortex. This is a structure inside the spore coat and surrounding the central core. Lewis, Snell \& Burr (1960) suggested that the core might have a low freewater content because it is squeezed dry by a contractile cortex. This presupposes that an early event in germination would be loss of strength of this structure, perhaps by lysis with release of hexosamine-containing peptides. Takagi, Kawata \& Yamamoto (1960) have shown that the cortex is disrupted early in the germination process, so this structure could equally well be enzymically weakened rather than the coat, and allow the core to swell. In any case, hydration and swelling of the core could then be reflected in swelling of the spore and a change to more spheri- 
cal shape as it became turgid. Some internal structure becomes visible in light-field photographs of Bacillus subtilis spores early in the germination process (Pl. 1) and is probably the core and cortex (Powell, 1957; Robinow, 1960). The core does not obviously swell in the first few minutes of germination; however, the structure surrounding it, which may be the cortex, does increase in thickness (Pl. 1).

In contrast to germination-swelling, pre-emergence (post-germination) swelling requires good aeration and an external energy source. Pre-emergence swelling is therefore probably due to synthesis coupled with uptake of water and is similar to the elongation process. Since Bacillus spores can germinate anaerobically (Roth \& Lively, 1956) and many species can outgrow in the absence of oxygen to give viable vegetative forms, pre-emergence swelling must be able to occur anaerobically but after a lag. Nevertheless, pre-emergence swelling needs external energy sources under anaerobiosis.

The prime event in germination is usually assumed to be something that causes a change in the permeability of the dormant spore. Murrell \& Scott (1958) demonstrated the permeability of dormant spores to water. Black \& Gerhardt (1962) showed that dormant spores are permeable to water, germination stimulants and non-germination stimulants. They listed the evidence for an increase in permeability during germination and demonstrated it for glucose and water in Bacillus cereus. Thus germination swelling is probably due to water uptake for rehydration of the spore, which is widely assumed to contain little free water, and is therefore an inseparable part of germination. As germination stimulants are utilized in almost undetectable amounts (Harrell \& Halvorson, 1955) and respiration is only just detectable during germination (Murrell, 1955) there may be an endogenous energy source and an electron acceptor taking the place of oxygen e.g. dipicolinic acid (Doi \& Halvorson, 1961). Thus although the breaking of the impermeability barrier may be metabolic, germination swelling is probably solely a consequence of physical rehydration.

We are grateful to Mr A. W. Knight for technical assistance.

\section{REFERENCES}

Black, S. H. \& Gerhardt, P. (1962). Permeability of bacterial spores. III. Permeation relative to germination. $J$. Bact. 83, 301.

Campbell, L. L., Jun. (1957). Bacterial spore germination-definitions and methods of study. In Spores, p. 33. Ed. by H. O. Halvorson, Washington D.C.: Amer. Inst. Biol. Sci.

Campbeld, L. L. \& SnIfF, E. E. (1959). Effects of subtilin and nisin on the spores of Bacillus coagulans. J. Bact. 77, 766.

Dor, R. H. \& Halvorson, H. (1961). Mechanism of dipicolinic acid stimulation of the soluble reduced diphosphopyridine nucleotide oxidase of spores. J. Bact. 81, 642 .

Halvorson, H. O. (1959). Symposium on initiation of bacterial growth. IV. Dormancy, germination, and outgrowth. Bact. Rev. 23, 267.

Harrell, W. K. \& Halvorson, H. (1955). Studies on the role of L-alanine in the germination of spores of Bacillus terminalis. J. Bact. 69, 275.

HyatT, M. T. \& Levinson, H. S. (1957). Sulphur requirement for postgerminative development of Bacillus megaterium spores. J. Bact. 74, 87.

HyatT, M. T. \& Levinson, H. S. (1959). Utilization of phosphates in the postgerminative development of spores of Bacillus megaterium. J. Bact. 77, 487 .

Levinson, H. S. \& HYATt, M. T. (1956). Correlation of respiratory activity with phases of spore germination and growth in Bacillus megaterium as influenced by manganese and L-alanine. J. Bact. 72, 176. 
Lewis, J. C., SNell, N. S. \& BurR, H. K. (1960). Water permeability of bacterial spores and the concept of a contractile cortex. Science, 132, 544.

Long, S. K. \& Williams, O. B. (1958). Method for removal of vegetative cells from bacterial spore preparations. J. Bact. 76, 332.

Mandels, G. R., Levinson, H. S. \& Hyatt, M. T. (1956). Analysis of respiration during germination and enlargement of spores of Bacillus megaterium and of the fungus Myrothecium verrucaria. J. gen. Physiol. 39, 310.

MoL, J. H. H. (1957). The temperature characteristics of spore germination and growth of Bacillus cereus. J. Appl. Bact. 20, 454.

MurReld, W. G. (1955). The Bacterial Endospore. Monograph, University of Sydney.

Murrell, W. G. \& ScotT, W. J. (1958). The permeability of bacterial spores to water. 7th int. Congr. Microbiol. Stockholm, p. 26.

Murty, G. G. K. \& Halvorson, H. O. (1957). Effect of enzyme inhibitors on the germination and respiration of and growth from Bacillus cereus var. terminalis spores. J. Bact. 73, 230.

Poweld, E. O. (1957). The appearance of bacterial spores under phase-contrast illumination. J. appl. Bact. 20, 342.

Powell, J. F. (1950). Factors affecting the germination of thick suspensions of Bacillus subtilis spores in L-alanine solution. J. gen. Microbiol. 4, 330.

Powell, J. F. \& Strange, R. E. (1953). Biochemical changes occurring during the germination of bacterial spores. Biochem. J. 54, 205.

Pulvertaft, R. J. V. \& Haynes, J. A. (1951). Adenosine and spore germination; phasecontrast studies. J. gen. Microbiol. 5, 657.

RoBinow, C. F. (1960). Morphology of bacterial spores, their development and germination. In The Bacteria, a Treatise on Structure and Function. Vol. I: Structure. Ed. I. C. Gunsalus and R. Y. Stanier. New York: Academic Press.

Rode, L. J. \& Foster, J. W. (1960). Mechanical germination of bacterial spores. Proc. nat. Acad. Sci., Wash, 46, 118.

Roth, N. G. \& Lively, D. H. (1956). Germination of spores of certain aerobic bacilli under anaerobic conditions. J. Bact. 71, 162.

Smith, N. R., Gordon, R. E. \& Clark, F. E. (1946). Aerobic mesophilic sporeforming bacteria. Misc. Publ. U.S. Dep. Agric. no. 559.

Strange, R. E. \& Dark, F. A. (1957 a). A cell-wall lytic enzyme associated with spores of Bacillus species. J. gen. Microbiol. 16, 236.

Strange, R. E. \& Dark, F. A. (1957b). Cell-wall lytic enzymes at sporulation and spore germination in Bacillus species. J. gen. Microbiol. 17, 525.

Takagi, A., Kawata, T. \& Yamamoto, S. (1960). Electron microscope studies on ultrathin sections of spores of the clostridium group, with special reference to the sporulation and germination process. J. Bact. 80, 37.

Wolf, J. \& MaHmoud, S. A. Z. (1957). The germination and enzymic activities of Bacillus spores at low temperatures. J. appl. Bact. 20, 124.

\section{EXPLANATION OF PLATES}

The scale marks represent $5 \mu$.

Plate 1. Germinating spores of Bacillus subtilis

Figs. 1-4. Phase-contrast photographs.

Figs. 5-8. Light-field photographs.

Figs. 1, 5. Ungerminated spores.

Figs. 2, 6. First signs of germination and swelling after $3 \mathrm{~min}$.

Figs. 3, 7. Core and cortex visible after $6 \mathrm{~min}$.

Figs. 4, 8. Spores fully germinated and swollen with core and cortex clearly visible after $10 \mathrm{~min}$. 
Journal of General Microbiology, Vol. 30, No. 3

Plate 1
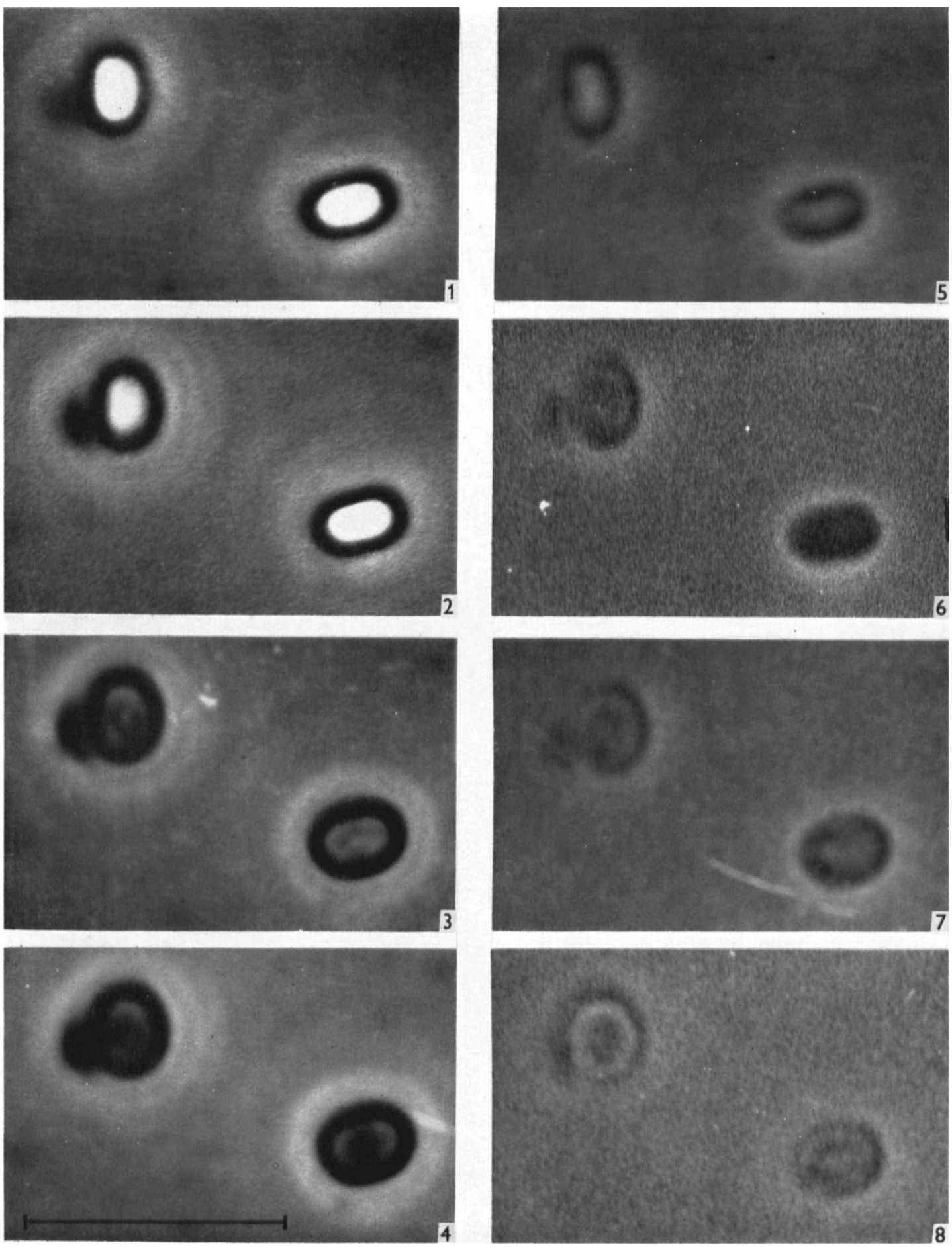

A. D. HITCHINS, G. W. GOULD AND A. HURST

(Facing p. 452) 
Journal of General Microbiology, Vol. 30, No. 3

Plate 2
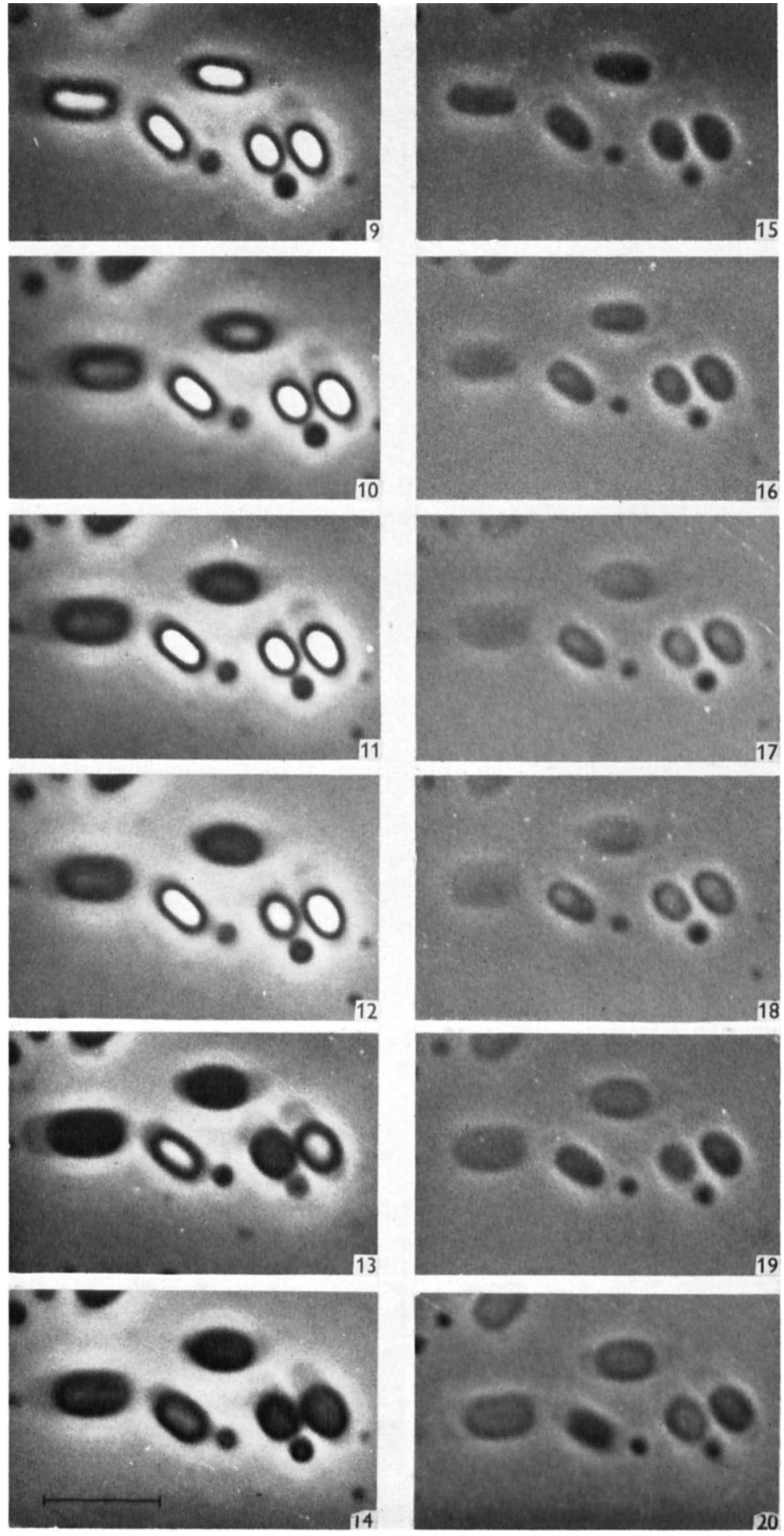

A. D. HITCHINS, G. W. GOULD AND A. HURST 
Plate 2. Germinating spores of Bacillus cereus

Figs. 9-14. Phase-contrast photographs.

Figs. 15-20. Light-field photographs.

Figs. 9, 15. Group of five ungerminated spores and two parasporal bodies. One spore is beginning to germinate and shows peripheral darkening by phase contrast. Exosporia are visible as pale sheaths interrupting the light haloes.

Figs. 10, 16. After $3 \mathrm{~min}$. germinating spores are swelling.

Figs. 11, 17. After 5.5 min.

Figs. 12, 18. After $8 \mathrm{~min}$.

Figs. 13, 19. After $13 \mathrm{~min}$.

Figs. 14, 20. After $18 \mathrm{~min}$. all spores have germinated. Core and cortex are not detectable. 